\title{
APLIKASI PENDUKUNG TAMAN BACAAN ANIME BANJARBARU
}

\author{
Adani Dharmawati, M.Kom \\ Fakultas Teknologi Informasi, Universitas Islam Kalimantan MAB Banjarmasin \\ Email : adani.dharmawati@gmail.com
}

\begin{abstract}
Abstrak
Usaha Kecil Menengah (UKM) Taman Bacaan Anime merupakan suatu badan usaha kecil menengah yang bergerak dibidang pelayanan jasa penyewaan komik, novel dan juga majalah komik yang masih menggunakan cara konvensional atau masih dicatat secara manual. Didalam upaya meningkatkan pengolahan, sistem peminjaman dan pendaftaran anggota adalah hal yang perlu ditingkatkan kinerjanya dengan membangun suatu aplikasi alat bantu yang dapat membantu memudahkan pekerjaan atau rutinitas dalam pengolahan data, transaksi peminjaman dan pengembalian dan pelaporan yang cepat tepat, akurat dan dapat dipercaya. Dalam kasus ini akan dibagun Sistem Informasi Taman Bacaan Anime.
\end{abstract}

Keywords : Taman Bacaan, peminjaman, pengembalian

\section{PENDAHULUAN}

Taman Bacaan Anime merupakan salah satu badan usaha kecil menengah yang bergerak dibidang pelayanan jasa penyewaan majalah, komik, dan novel. Taman Bacaan Anime ini sudah melakukan pengkodean terhadap anggota dan juga koleksi tetapi masih menggunakan cara konvensional atau masih dicatat secara manual di beberapa buku induk. Sedangkan pencatatan transaksi hanya dilakukan pada selembaran kertas transaksi yang dimiliki tiap anggota.

Sistem pencatatan koleksi, anggota, dan juga transaksi masih menggunakan media manual sehingga sulit untuk mencari data yang diinginkan. Disamping itu juga sulit untuk mencari anggota yang masuk jatuh tempo, sehingga bagian pelayanan tidak bisa memberikan peringatan terhadap anggota tersebut. Alhasil, banyak anggota yang denda bahkan tidak mengembalikan koleksi sama sekali

Selain itu, sistem tidak ada mencatatat koleksi apa saja yang belum tersedia sehingga sulit untuk memenuhi seluruh permintaan koleksi dari anggota. Sistem juga masih membuat laporan secara manual, dan itu memerlukan waktu yang cukup lama dan rentan kesalahan.

Jurnal Ilmiah "Technologia"
Didalam upaya meningkatkan pengolahan data koleksi dan anggota, sistem transaksi peminjaman dan pengembalian, beserta pembuatan laporan secara otomatis meruapakan hal yang perlu ditingkatkan kinerjanya dengan membangun suatu aplikasi alat bantu yang dapat membantu memudahkan pekerjaan atau rutinitas dalam pengolahan data dan pelaporan yang cepat tepat, akurat dan dapat dipercaya. Dalam kasus ini akan membangun Sistem Informasi Taman Bacaan Anime.

Aplikasi ini adibuat menggunakan Borland Delphi 7.0. Umumnya delphi hanya digunakan untuk pengembangan aplikasi desktop, enterprise berbasis database dan programprogram kecil. Namun karena pengembangan Delphi yang semakin pesat dan bersifat general purpose, bahasa pemprograman ini mampu digunakan untuk berbagai jenis pengembangan software dan Delphi juga disebut sebagai pelapor perkembangan RatTool (Rapid Apllication Development) tahun 1995.[1] Sehingga banyak orang yang mulai mengenal dan menyukai bahsa pemprograman yang mulai mengenal dan menyukai bahasa pemprograman yang bersifat VCL (Visual Component Library) [2].

Microsoft Office Access adalah program pengolahan database yang sangat populer. Program ini merupakan salah satu program 
aplikasi yang berada dalam keluarga Microsoft Office. Saat ini cukup banyak pengguna Microsoft Access yang hanya menggunakan program ini untuk membuat table databse, padahal dalam Microsoft Access tersedia banyak fasilitas yang dapat digunakan untuk memaksimalkan pembuatan laporan yang dibuat dalam bentuk Query, Form, atau Report.[3] Salah satu fasilitas yang disediakan Microsoft Access adalah fungsi. Microsoft Access menyediakan banyak fungsi yang dikelompokkan beberapa kategori untuk melakukan proses kalkulasi data [4].

Perlu adanya penelitian tentang bagaimana membangun sistem informasi untuk membantu proses pendataan dan juga proses transaksi pada Taman Bacaan Anime Banjarbaru.

Tujuan dari penelitian ini adalah membangun sistem informasi untuk membantu proses pendataan dan juga proses transaksi pada Taman Bacaan Anime menggunakan cara komputerisasi dan terintegrasi dalam sebuah database.

Target luaran dalam pembuatan laporan penelitian ini adalah untuk sistem informasi untuk membantu proses pendataan dan juga proses transaksi pada Taman Bacaan Anime Banjarbaru. Adapun manfaat dari penelitian ini adalah sebagai berikut:

1. Memberikan kemudahan dalam pendataan koleksi, anggota, dan permintaan.

2. Memudahkan transaksi peminjaman dan pengembalian.

3. Membantu dalam menyusun laporan koleksi, anggota, permintaan dan jatuh tempo.

4. Membantu dalam backup data.

5. Memberikan informasi yang lebih cepat dengan menggunakan aplikasi berbasis teknologi komputer.

\section{METODE PENELITIAN}

Data yang digunakan dalam penelitian ini berupa data primer dan data sekunder. Data primer berupa data yang diperoleh secara langsung dari Taman Bacaan Anime Banjarbaru. Dan data sekunder berupa data yang diperoleh pada saat dilakukan penelitian. Adapun dalam melakukan pengumpulan data digunakan beberapa cara antara lain:

\section{a. Observasi}

Yaitu metode untuk mendapatkan data dengan melakukan pengamatan langsung di Taman Bacaan Anime Banjarbaru. Dari observasi ini dapat diketahui proses bisnis yang terjjadi, dimulai dari pendatan koleksi, anggota, transaksi peminjaman dan transaksi pengembalian..

b. Studi Pustaka

Studi pustaka dilakukan dengan mengumpulkan data yang dilakukan dengan mencari literature, data-data dari buku-buku, dan kepustakaan lainnya yang berhubungan dengan penelitian ini.

c. Wawancara

Yaitu melakukan tanya jawab terhadap pemilik usaha dan staf yang bekerja di Taman Bacaan Anime Banjarbaru

\section{HASIL DAN PEMBAHASAN}

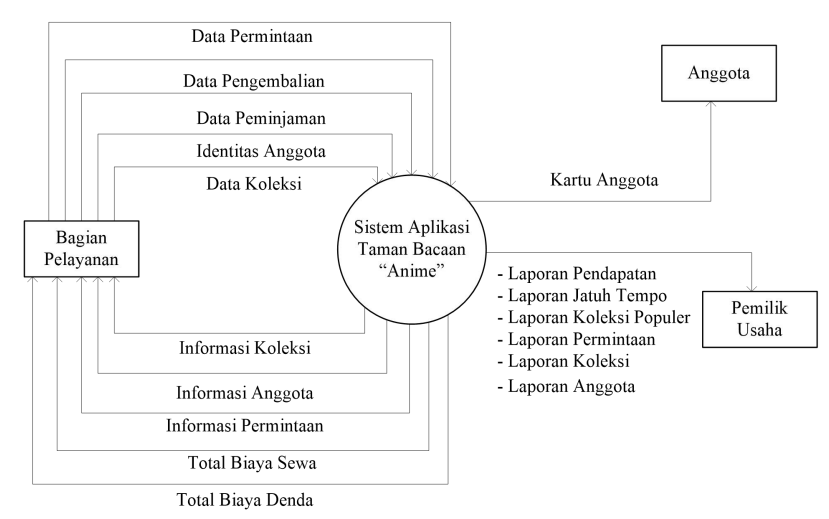

Gambar 1. Diagram Konteks

Diagram konteks memberikan gambaran umum mengenai interaksi yang terjadi antara sistem, admin, anggota dan pemilik usaha. Diagram konteks dari sistem ini ditunjukkan pada gambar 1 .

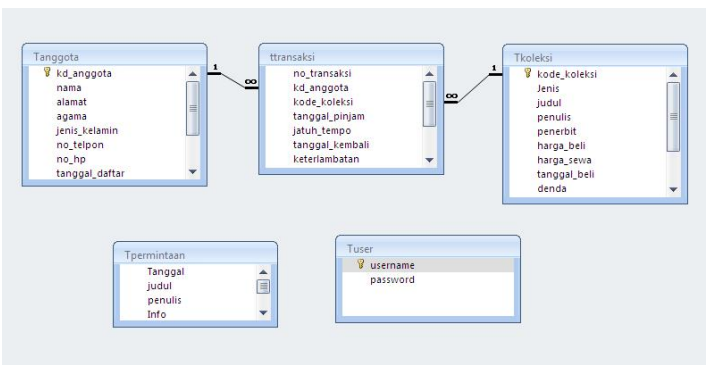




\section{Gambar 2. Relasi Tabel}

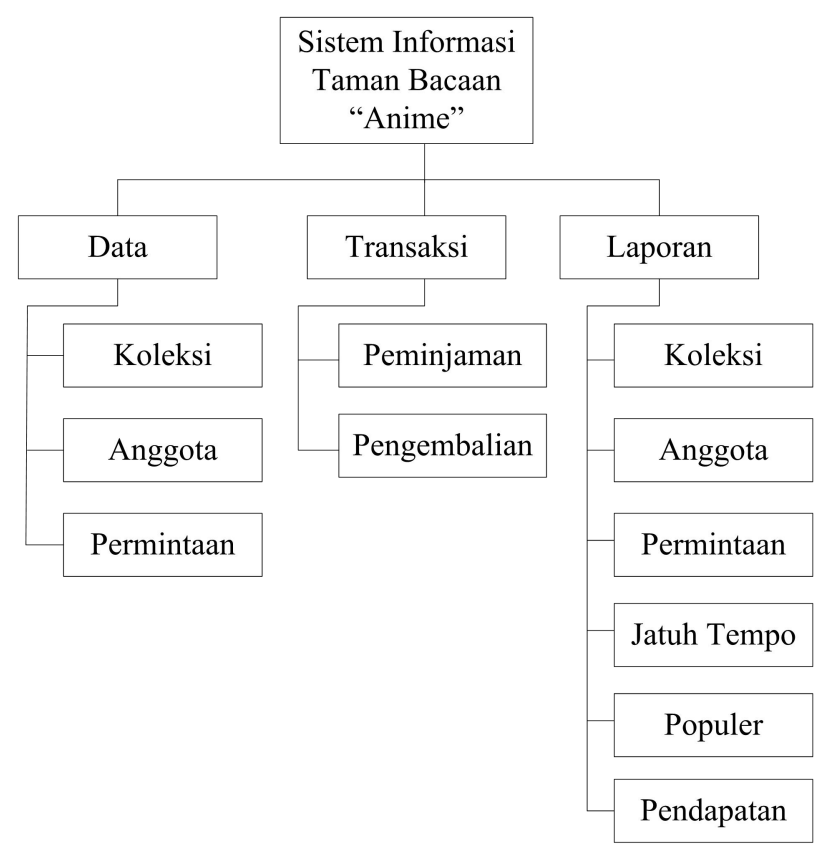

Gambar 3. Desain Arsitektural

Sebelum masuk ke sistem, user akan diminta login dengan memasukkan usrname dan password. Jika benar, maka tampilan halaman utama akan muncul.

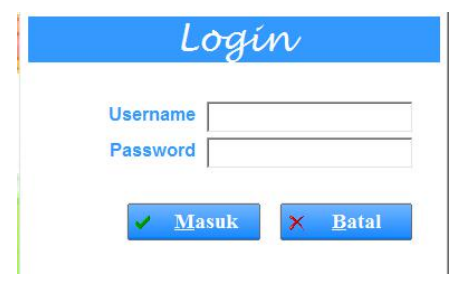

\section{Gambar 4. Form Login}

Berikut merupakan halama utama yang berisikan 4 menu adan beberapa sub menu ditiap menu tersebut.

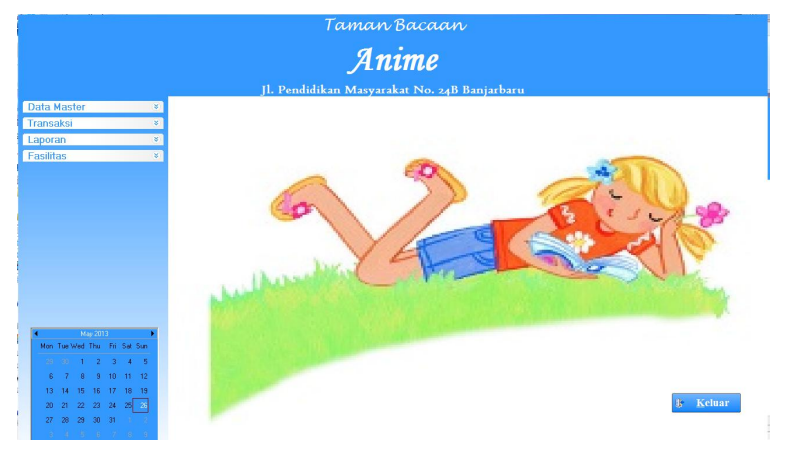

\section{Gambar 5. Form Menu Utama}

Di menu Data, sub menu pertama yaitu Data Koleksi. Disini user bisa menambah, menghapus, mengubah, dan melihat data koleksi.

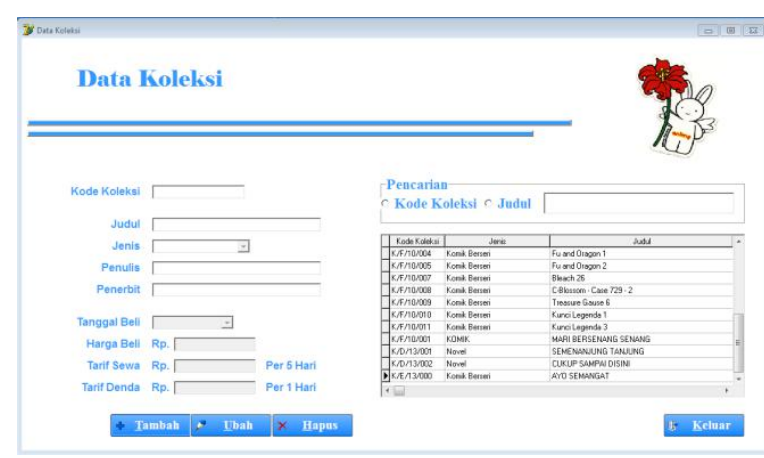

\section{Gambar 6. Form Data Koleksi}

Kemudian, masih dimenu Data, submenu selanjutnya yaitu Data Anggota. Disini user bisa menambah, menghapus, mengubah, dan melihat data anggota.

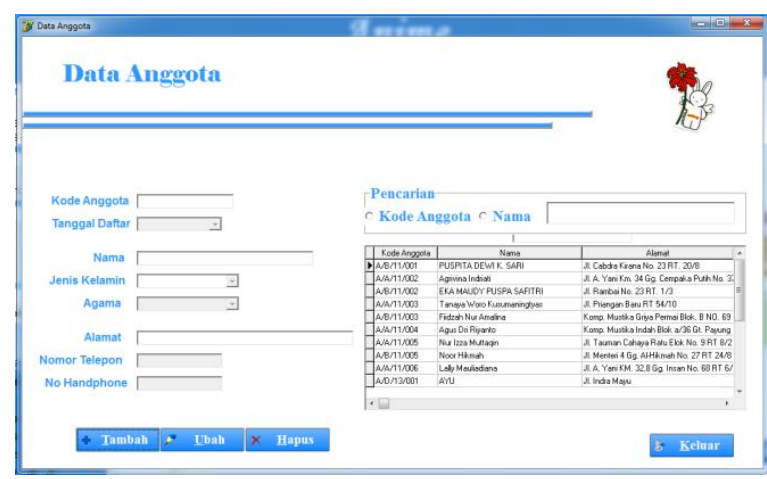

\section{Gambar 7. Form Data Anggota}

Selanjutnya, sub menu terakhir yang ada di menu Data yaitu Data Permintaan. Disini user bisa menambah, menghapus, mengubah, dan melihat data permintaan koleksi dari para anggota. 


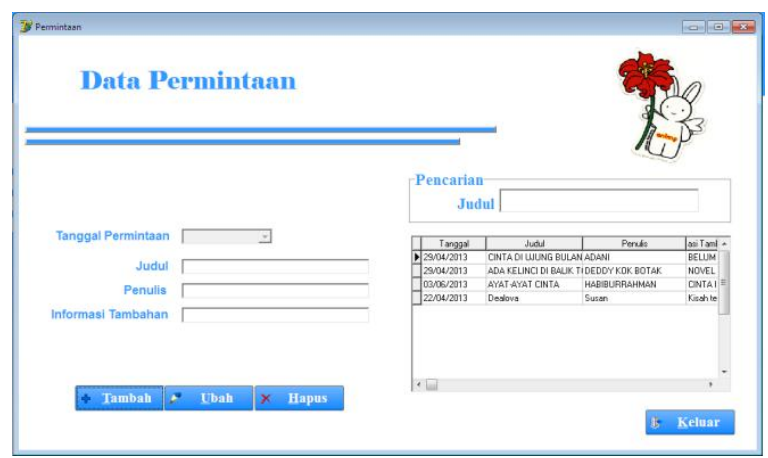

Gambar 8. Form Data Permintaan

Kemdian, kita beralih ke menu selanjutnya, yaitu menu transaksi. Sub menu pertama yang akan kita jumpai yaitu Transaksi Peminjamaan. Disinilah proses transaksi peminjaman koleksi yang dilakukan para anggota akan dimasukkan.

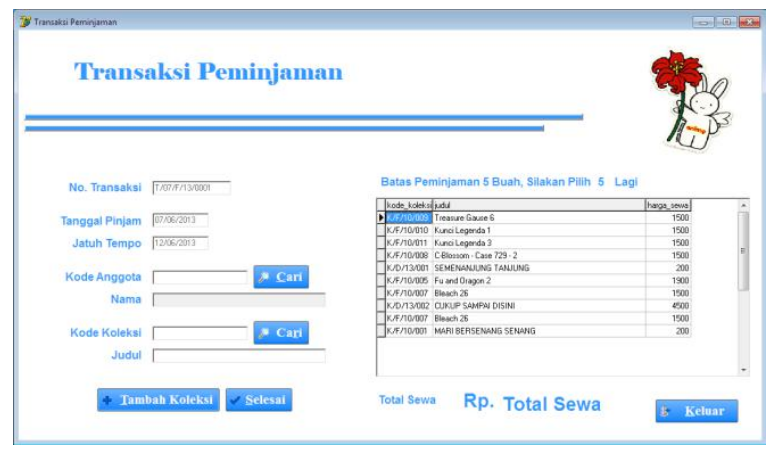

Gambar 9. Form Transaksi Peminjaman

Didalam sub menu Transaksi Peminjaman, terdapat dua buah form bantu yang digunakan untuk mencari data anggota yang akan meminjam dan juga mencari data koleksi yang akan dipinjam.

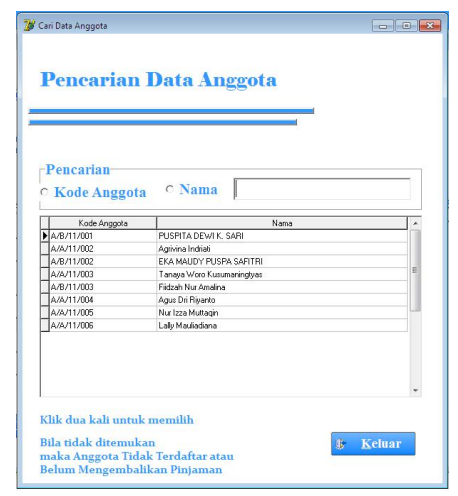

Gambar 10. Form Pencarian Anggota

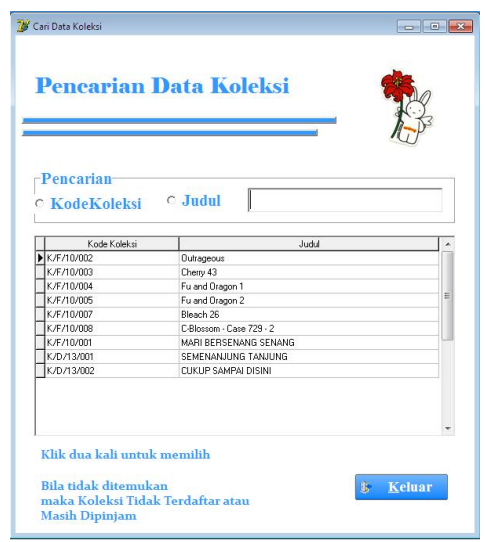

Gambar 11. Form Pencarian Koleksi

Selanjutnya, sub menu kedua yang ada di menu Transaksi yaitu Transaksi Pengembalian. Disinilah proses transaksi pengembalian koleksi yang dilakukan para anggota akan dimasukkan.

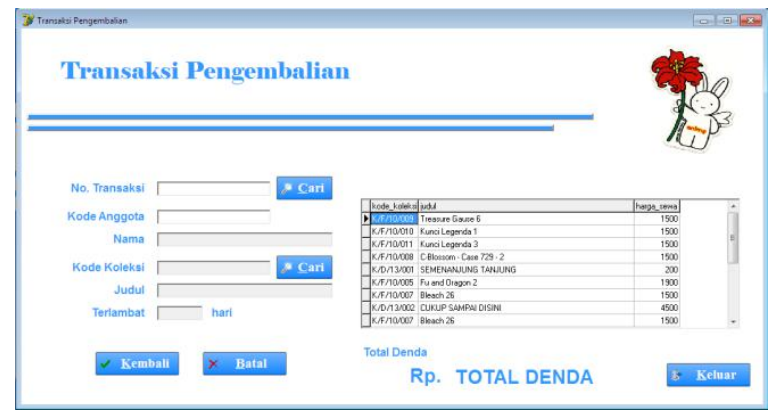

\section{Gambar 12. Form Transaksi Pengembalian}

Didalam sub menu Transaksi Pengembalian, juga terdapat dua buah form bantu yang digunakan untuk mencari data anggota yang akan mengembalikan koleksi dan juga mencari data koleksi yang akan dikembalikan.

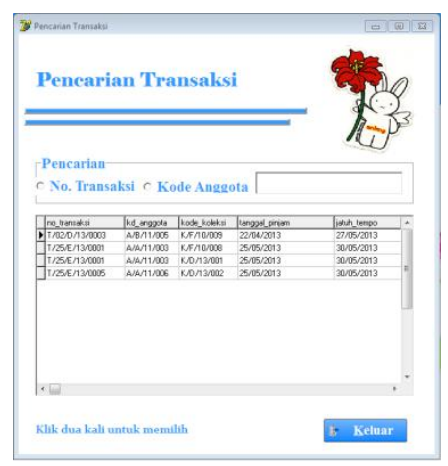

Gambar 13. Form Pencarian Transaksi 


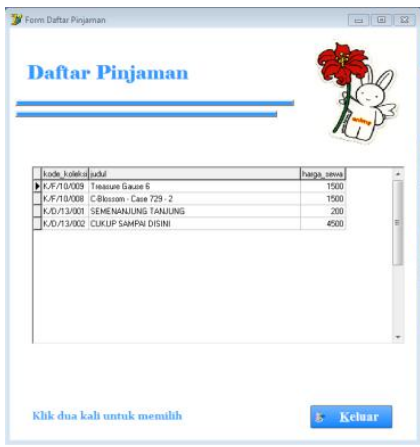

Gambar 14. Form Daftar Pinjam

Menu selanjutnya yautu Laporan. Di menu ini, sub menu pertama yaitu Laporan Koleksi. Disini kita bisa melihat dan mencetak semua data koleksi yang ada.

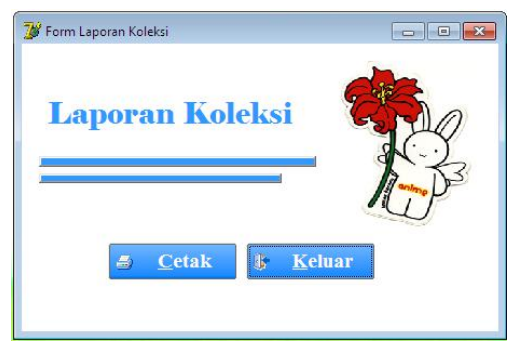

Gambar 15. Form Laporan Koleksi

Dan berikut ini merupakan tampilan laporan yang akan dihasilkan.

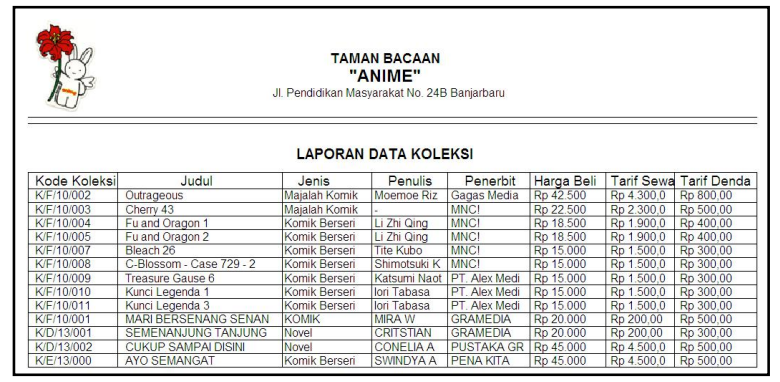

\section{Gambar 16. Laporan Koleksi}

Sub menu selanjutnya yang ada di menu Laporan yaitu Laporan Anggota. Disini kita bisa melihat dan mencetak semua data anggota.

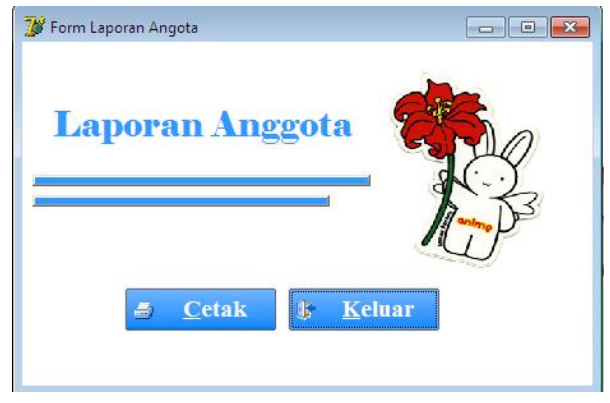

Gambar 17. Form Laporan Anggota

Dan berikut ini merupakan tampilan laporan yang akan dihasilkan

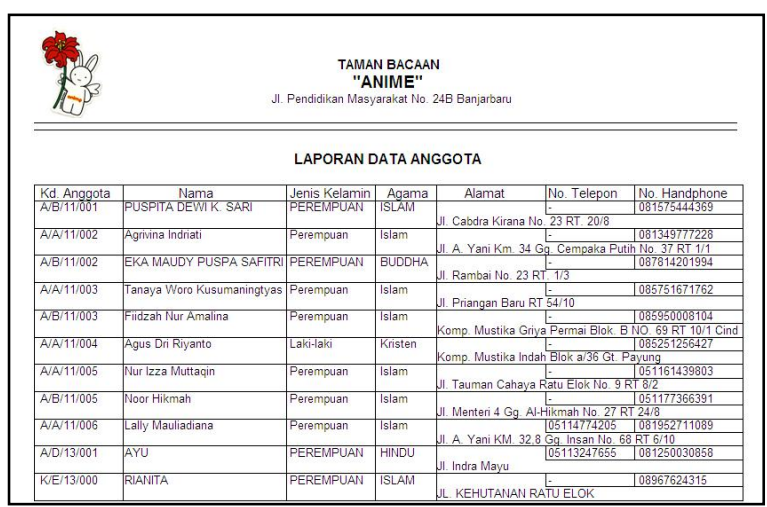

\section{Gambar 18. Laporan Anggota}

Sub menu selanjutnya yang ada di menu Laporan yaitu Laporan Permintaan. Disini kita bisa melihat dan mencetak semua data permintaan koleksi yang diajukan oleh anggota.

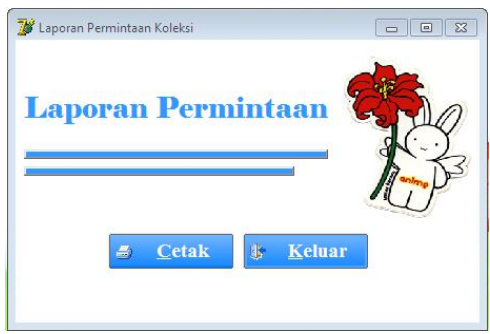

\section{Gambar 19. Form Laporan Permintaan}

Dan berikut ini merupakan tampilan laporan yang akan dihasilkan. 


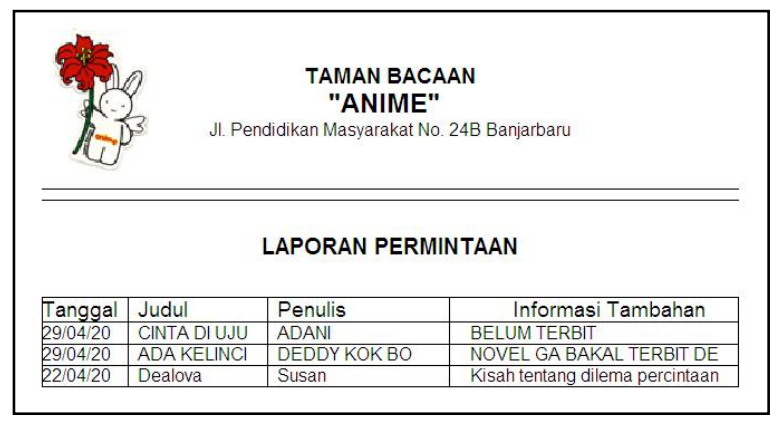

\section{Gambar 20. Laporan Permintaan}

Sub menu selanjutnya yang ada di menu Laporan yaitu Laporan Jatuh Tempo. Disini kita bisa melihat dan mencetak semua data peminjaman koleksi yang telah jatuh tempo atau sudah melewati batas pinjam namun belum dikembalikan.

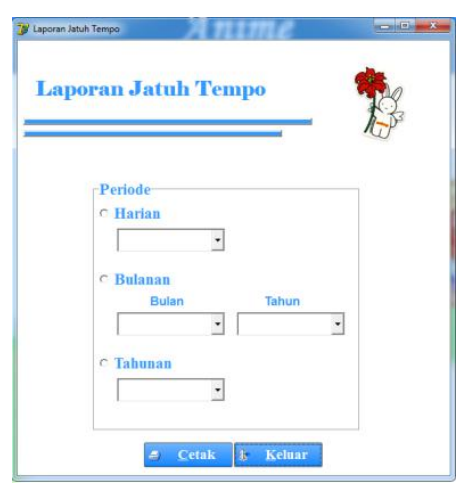

Gambar 21. Form Laporan Jatuh Tempo

Dan berikut ini merupakan tampilan laporan yang akan dihasilkan.

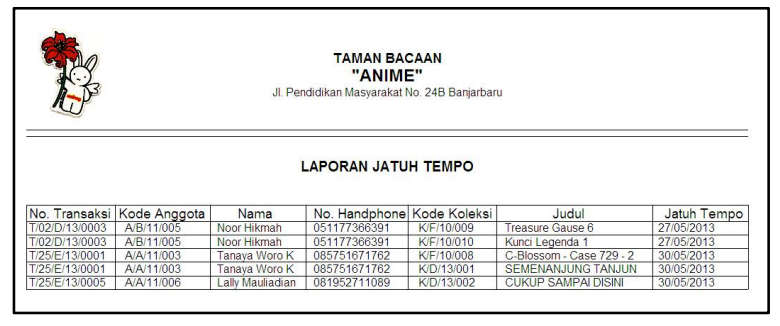

Gambar 22. Laporan Jatuh Tempo

\section{KESIMPULAN}

Dengan adanya sistem informasi untuk membantu proses pendataan dan juga proses transaksi pada Taman Bacaan Anime Banjarbaru.
Dapat disimpulkan bahwa aplikasi yang dibangun sudah sesuai dengan tujuan yaitu untuk membantu proses pendataan dan juga proses transaksi pada Taman Bacaan Anime menggunakan cara komputerisasi dan terintegrasi dalam sebuah database. Serta dapat membantu dalam menyusun laporan koleksi, anggota, permintaan dan jatuh tempo dengan cepat.

Untuk penelitian selanjutnya diharapkan mengembangkan aplikasi pendukung taman bacaan Anime ini dapat dilanjuykan sampai perhitungan keuntungan yang diapat. Disamping itu diharapkan adanya perbaikan dari segi desain aplikasi maupun dengan penambahan fitur lainnya sehingga dapat menampilkan aplikasi yang lebih baik dari yang sebelumnya.

\section{REFERENSI}

[1] Eko Indriyawan, Fransisca Aure Liasie, Tomi Sayugo. 2011. MasteringDelphi 7. Andi Publisher.

[2] Rahman, A., \& Akhmad, J. (2013). Aplikasi persetujuan pasang baru listrik wilayah Banjarbaru. Banjarbaru: Stmik Banjarbaru.

[3] Kadir, Abdul. 2003. Penuntun Praktis Belajar Database MenggunakMicrosoft Access. Andi Offset. Yogyakarta.

[4] MADCOMS, L. (2005). Rumus dan Fungsi Pada Microsoft Access. Yogyakarta: Andi. 